$$
\text { Pontifícia Universidade C Católica }
$$

Sabrina Alvernaz Silva

\title{
Las kenningar: linguagem e perspectivismo
}

\section{Dissertação de Mestrado}

Dissertação apresentada ao Programa de Pós-graduação em Letras da PUC-Rio como requisito parcial para obtenção do título de Mestre em Letras.

Orientadora: Profa. Helena Franco Martins 


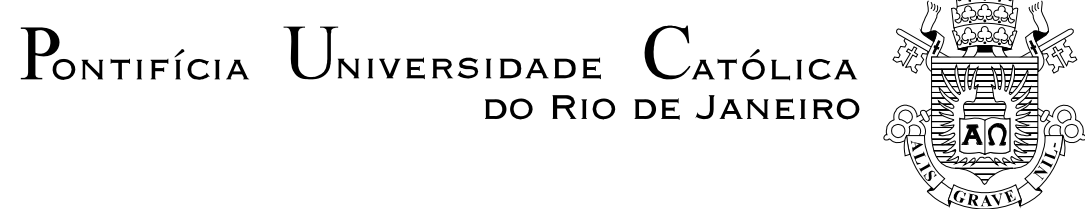

Sabrina Alvernaz Silva

\section{Las kenningar: linguagem e perspectivismo}

Dissertação apresentada como requisito parcial para obtenção do grau de Mestre pelo programa de Pós-Graduação em Letras do Departamento de Letras do Centro de Teologia e Ciências Humanas da PUC-Rio. Aprovada pela Comissão Examinadora abaixo assinada.

Prof. Helena Franco Martins

Orientadora

Departamento de Letras - PUC-Rio

Prof. Marília Rothier Cardoso

Departamento de Letras - PUC-Rio

Prof. Márcia Atálla Pietroluongo

UFRJ

Profa. Denise Berruezo Portinari Coordenadora Setorial do Centro de Teologia

e Ciências Humanas - PUC-Rio

Rio de Janeiro, 23 de março de 2011 
Todos os direitos reservados. É proibida a reprodução total ou parcial do trabalho sem autorização da universidade, da autora e do orientador.

\section{Sabrina Alvernaz Silva}

Graduou-se em Letras pela UERJ em 2008. Concluiu o mestrado em Letras na área de Estudos da Linguagem da PUCRio em 2011. Durante a realização do mestrado participou do programa de intercâmbio acadêmico PUC-UNR desenvolvendo parte de sua pesquisa no departamento de Letras da Universidad Nacional de Rosario, na Argentina.

Ficha Catalográfica

Silva, Sabrina Alvernaz

Las Kenningar: linguagem e perspectivismo / Sabrina Alvernaz Silva ; orientadora: Helena Franco Martins. 2011.

$$
120 \mathrm{f.} \mathrm{;} 30 \mathrm{~cm}
$$

Dissertação (mestrado) - Pontifícia Universidade Católica do Rio de Janeiro, Departamento de Letras, 2011.

Inclui bibliografia

1. Letras - Teses. 2. Kenningar. 3. Metáfora. 4.

Perspectivismo. 5. Borges, Jorge Luis, \$d 1899-1986. I. Martins, Helena Franco. II. Pontifícia Universidade Católica do Rio de Janeiro. Departamento de Letras. III. Título.

CDD: 400 


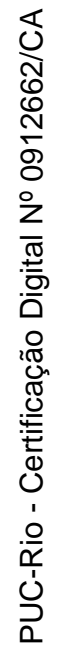

Para os meus pais 


\section{Agradecimentos}

Aos meus pais, Leo (abrigo das tormentas) e Mair (heroína do sobrenatural), a quem amo infinitamente e de quem muito me orgulho.

Ao igualmente amado Thelmo (yelmo < elmo < mô) por sua imprescindível presença.

Às queridas irmãs Gabi e Deby por serem minhas amigas e companheiras.

Às amigas Paty e Kelly que se tornaram fundamentais na minha marcha.

À Matilde e à Elisa pelos incansáveis exemplos de altruísmo e amizade.

Às meninas do ap (Renatinha, Kaká, Lis e Aninha), À Silvia, à Karlinha, à Manu, à Nathalia agradeço pelos botes salva-vidas.

À Helena Martins, pelas aulas que arrebatavam o ar, pelo exemplo de escrita e pela confiança ao aceitar o convite para orientar-me, sem a qual esta pesquisa não seria possível.

À professora Marília Rothier por ter sido uma bússola e um rio em meio ao deserto. Agradeço, além de todo o restante, pela inspiração.

À professora Sandra Contreras que contribuiu para que o intercâmbio com a UNR resultasse num produtivo crescimento acadêmico. Agradeço as sugestões, as leituras, os livros, enfim, todas as importantes contribuições.

A Borges e a Viveiros de Castro por me impulsionarem a uma caminhada intelectual. Reconheço aqui muitíssimas dívidas.

Às professoras que aceitaram, gentilmente, participar da Comissão examinadora.

À querida Chiquinha por seu trabalho impecável.

Ao CNPq e à PUC-Rio, pelos auxílios concedidos, sem os quais este trabalho não poderia ter sido realizado.

A Jesus Cristo (queria encontrar palavras: o Fiel, o Salvador, o Consolador... mas, minha tentativa de definição, como sempre, fica muito aquém). 


\section{Resumo}

Silva, Sabrina Alvernaz; Martins, Helena Franco. Las kenningar: linguagem e perspectivismo. Rio de Janeiro, 2011. 120p. Dissertação de Mestrado Departamento de Letras, Pontifícia Universidade Católica do Rio de Janeiro.

Esta dissertação analisa o ensaio Las kenningar, de Jorge Luis Borges. Debruçando-nos sobre suas reflexões acerca desse recurso próprio dos poemas medievais islandeses, encontramos vez para discutir a linguagem, em geral, e a metáfora, em particular. Mostraremos mais especificamente que certo ângulo aberto pelo texto de Borges permite pensá-las de uma forma que é surpreendentemente próxima do tipo de perspectivismo descrito pelo antropólogo Eduardo Viveiros de Castro em suas reflexões sobre a vida e o pensamento ameríndio. Tal afinidade é fomentada por inusitados encontros: se o "sangue”, por exemplo, nas kenningar, pode ser “a cerveja dos corvos”; para os ameríndios, pode ser o “cauim do jaguar”. Destaca-se nos dois casos, conforme mostraremos, o privilégio de uma perspectiva e a predominância das relações em devir - e isso de um modo que promete subverter de forma especialmente radical o pendor logocêntrico, que tende a permanecer como “matéria velha” em percepções contemporâneas ocidentais sobre a palavra, mesmo entre os mais perseverantes críticos da visão representacionista da linguagem. Busca-se mostrar também como o ensaio de Borges, na contraluz do perspectivismo ameríndio, abre espaços para se repensar o jogo entre metáfora e alteridade.

\section{Palavras-chave}

kenningar; metáfora; perspectivismo; Borges. 


\section{Abstract}

Silva, Sabrina Alvernaz; Martins, Helena Franco (Advisor). Las kenningar: language and perspectivism. Rio de Janeiro, 2011. 120p. MSc. Dissertation - Departamento de Letras, Pontifícia Universidade Católica do Rio de Janeiro.

This dissertation analyses Jorge Luis Borges’ essay Las kenningar. Looking on his reflexions about the kenningar - a resource typical to the icelandic medieval poetry -, a discussion on language, in general, and on metaphor, in particular, arises. It is shown specifically that an angle explored by Borges allows to think metaphor in a very close way to anthropologist Eduardo Viveiros de Castro's perspectivism definition as found in his works on Amerindian people life and mind. Such an affinity is fomented by amusing encouters, e.g. if "blood" in the kenningar can be “crows' beer”, to Amerindian people it can be "jaguar's cauim”. In both cases, it will be shown that a certain perspective is privileged and that becoming relationships are dominant. All this ocurrs in a specially radical way that promises to subvert the logocentric penchant - which becomes "old stuff” in the contemporary western perceptions about language. It also tries to show how Borges' essay along with Amerindian perspectivism call for a rethinking of the metaphor/alterity game.

\section{Keywords}

Kenningar; metaphor; perspectivism; Borges. 


\section{Sumário}

$\begin{array}{ll}\text { 1. Introdução } & 10\end{array}$

2. O que as kenningar forjam 13

2.1. O caráter relacional dos nomes 33

2.2. Las kenningar diante do impasse metafórico em Borges 39

3. Sentido e perspectiva 51

3.1. O Perspectivismo ameríndio com seu multinaturalismo 51

3.2. Quando o sangue é cauim 61

3.3. Mundos em devir: Tlön, Funes e kenningar 75

4. A constituição do eu pelo outro: alteridade e identidade no encontro de Castro e Borges

5. Considerações Finais 102

6. Referências Bibliográficas 105

$\begin{array}{lr}\text { 7. Anexo } & 109\end{array}$ 


\section{Lista de abreviaturas}

Obras de Jorge Luis Borges

K - "Las kenningar". In: História da eternidade (1999a).

LGM - Literaturas Germánicas Medievales (1999b).

Obras de Eduardo Viveiros de Castro

IAS - A Inconstância da Alma Selvagem - e outros ensaios de antropologia, Viveiros de Castro (2002).

E - Encontros (2008). 